\title{
SYSTEMIC NICOTINE ADMINISTRATION SUPPRESSES FOOD INTAKE VIA REDUCED MEAL SIZES IN BOTH MALE AND FEMALE RATS
}

\author{
Vladimír Bláha, Zhong-jin Yang ${ }^{1}$, Michael Meguid ${ }^{1}$, Jia-ke Chai ${ }^{1}$ and Zdeněk Zadák \\ Department of Metabolic Care and Gerontology, Charles University, Faculty of Medicine and Teaching Hospital, \\ Hradec Králové, Czech Republic; (Head: prof. MUDr. Z. Zadák, CSc.) \\ Neuroscience Program, Surgical Metabolism and Nutrition Laboratory, Department of Surgery, University Hospital, \\ SUNY Health Science Center, Syracuse, NY 13210, USA; (Head: prof. J. Parker, MD, PhD) ${ }^{1}$
}

\begin{abstract}
Summary: The appetite suppressing effect of tobacco products, via the main pharmacological agent nicotine, is a major reason for its usage both by woman and man. Food intake (FI) could be changed by altering either meal size (MZ) or meal number (MN), which are regulated dependently in a reciprocal manner. The present study investigated the effect of systemic nicotine administration on the rat feeding pattern. Because of gender differences in the effects of nicotine, both male and female rats were studied. Alzet mini-osmotic pumps (Model 2001) and the automated rat eatometer were used to evaluate the feeding pattern of male and female Fischer 344 rats during seven days of systemic nicotine infusion $(6 \mathrm{mg} / \mathrm{kg}$ b.w. s.c.). The main findings are: 1) systemic nicotine infusion decreased food intake in both sexes; 2) the decreased food intake was due to significantly reduced meal sizes while meal numbers were not altered significantly in either males or females; 3 ) the cyclical pattern of vaginal smears, food intake, meal number and meal size of female rats was not affected by nicotine administration. We conclude that the feeding suppressive effect of nicotine, which is due to reduced meal sizes and thus satiation, is not sex-hormones related.
\end{abstract}

Key words: Nicotine; rats; Male and female; Feeding pattern; Meal size; Meal number; Food intake; Mini-osmotic pump

\section{Introduction}

The appetite suppressing effect of smoking, via its main pharmacological agent nicotine, is used by both woman and man to control their food intake and body weight (33). Chronic nicotine administration has been found in rats and humans to cause reduced body weight which may also be accompanied by reduced food intake and water intake $(1,8,9,17,23,33)$

Behavioral studies have shown that chronic nicotine administration decreased both the time spent investigating the food and the amount of food consumed (16). Nevertheless, the effects of nicotine on particular feeding patterns, e.g. meal number (MN) and meal size (MZ), were rarely studied in detail. Since food intake (FI) is the product of meal size $(\mathrm{MZ})$ and meal number $(\mathrm{MN})$ [FI=MZxMN], it has been shown previously $\mathrm{MZ} / \mathrm{MN}$ varies in a reciprocal manner in a variety of experimental conditions which affect food intake (6). Thus under pathological conditions, depending on the stimulus, a decrease in food intake may be accomplished via a decrease in meal number, meal size, or both to varying degrees which probably reflect their separate hypothalamic control areas $(6,20,21,22,39)$.
Additionally, some sex differences in the effects of nicotine per se were reported in human studies of smoking behavior (13) and of sex-dependent metabolism and excretion of nicotine $(2,3,28)$. Animal studies of food consumption during nicotine administration showed contrasting results, depending not only on the experimental conditions, dose of nicotine, age, but also on the sex $(8,9,16,17,18,23$, $37)$. As has been recently reported, the female estrous cycle significantly affects meal number and meal size in a reciprocal fashion $(14,32)$. The food intake and feeding pattern in the female rat is related to the fluctuations in the circulating titers of sex-linked hormones (4). Low food intake during proestrous phase matched the smallest $\mathrm{MZ}$ and the highest MN during the late proestrous and early estrous phase (4). Therefore, the sex difference in nicotine sensitivity and its effect on feeding may result from endocrinological differences; other possibilities include receptor-binding differences, drug transport differences, differencies in feeding-related neurotransmission or, most probably, combination of several mechanisms (reviewed in 31).

Based on these observations, the present study was designed using an osmotic mini-osmotic pump implant technique: (i) to investigate the manner whereby systemic 
nicotine acts on the rat feeding pattern to suppress appetite; (ii) to study gender differences, if any, whereby nicotine influences the feeding pattern in male and female rats; (iii) to see whether nicotine decreases FI by affecting postprandial satiety and hunger via decreasing $\mathrm{MN}$, or by introducing premature satiation thereby decreasing $\mathrm{MZ}$, or both.

\section{Material and methods}

\section{Subjects}

Adult male and female Fischer-344 rats (Taconic Farm Co., Germantown, NY, male weighing 250-270g; female weighing 140-160 g; 10 wks old) were housed in holding cages for $1 \mathrm{wk}$ after purchase to acclimate them to the constant study environmental conditions: 12-h light-dark cycle (lights on at 0600 ), $26 \pm 1{ }^{\circ} \mathrm{C}$ room temperature, and $45 \%$ humidity. Tap water and standard rat chow (diet 5008, Ralston Purina, St. Louis, MO) were available ad libitum.

After initial acclimation, rats were placed in individual cages equipped with an automated computerized rat eater meter (ACREM), previously described in detail (19).

\section{Measurement of feeding pattern}

Food intake and feeding-related indexes were measured continuously and expressed per $24 \mathrm{~h}$ study period. The following indexes were measured: food intake $(\mathrm{FI} ; \mathrm{g})=$ amount of food consumed per study period; meal number $=$ total number of meals in each study period $(\mathrm{MN})$; and meal size $(\mathrm{MZ} ; \mathrm{g} /$ meal $)=$ total amount of food consumed per total meal number in each study period. Food intake comprised a series of bites. A bite was defined as an access to the food dish that resulted in food consumption $\geq 80 \mathrm{mg}$. Consequently, a meal was defined as a bite or a series of bites preceded and followed by at least 5 min of feeding inactivity $(19,20)$.

\section{Vaginal smears}

Female rats, showing regular 5 days cycling, were used in the study. Female estrous cycles were monitored by daily vaginal smears, done between 0800 and 1000 AM. After being stained, smears were observed under light microscopy, and the phase of the estrous cycle was determined. Briefly, metestrous phase was identified by the presence of pavement cells only; diestrous phase was identified by the presence of mostly polymorphonuclear leukocytes present with little or no mucus; proestrous phase was identified by the presence of polymorphonucleated leukocytes, nucleated cells and a few cornified epithelial cells present together with stringy mucus, and on late proestrous only with nucleated cells present; and estrous phase was identified when cornified epithelial cells were only present, except in the very early stages when a few irregularly shaped nucleated cells may also be seen (35).

\section{Nicotine administration}

Alzet mini-osmotic pumps (Model 2001) were implanted subcutaneously to deliver nicotine solutions or saline at a constant rate of $1 \mu \mathrm{l} / \mathrm{h}$ for 7 days. Physiological saline was used to prepare the nicotine solutions and was the control solution. Animals received $6 \mathrm{mg}$ of nicotine ([-]Nicotine Hydrogen Tartrate Salt, Sigma, St. Louis, MO) per kg body weight per day (nicotine group) or saline (control group).

\section{Experimental Design}

After an initial acclimatization period, daily measurements of food intake and feeding patterns were done using the ACREM (19). Body weights were recorded daily.

The rats were randomly assigned to the four experimental groups: controls infused with saline (male control, $\mathrm{n}=4$; female control, $\mathrm{n}=8$ ) or nicotine infused rats (male nicotine, $n=5$; female nicotine, $n=8$ ). Because of cycling in females, control data were collected from Day -6 to Day -1 .

On Day 0, the rats had Alzet mini-osmotic pumps implanted under Fenthrane inhalation anaesthesia. Each of the female rat was operated upon at the day of metestrous, to synchronize its estrous-cycle dependent food intake, meal number and meal size. The skin in the operation area was shaved and prepared with Povidone-Iodine 10\% (Betadine ${ }^{\circledR}$ ). Mini-osmotic pumps were placed subcutaneously in the nape of the neck by making a small incision (roughly $1 \mathrm{~cm}$ ), inserting the pump, and closing the incision with $9 \mathrm{~mm}$ wound clips. Food intake, feeding patterns and body weights were recorded for the following seven days during nicotine or saline infusion (Day 1 to Day 7).

On Day 8, the minipumps were removed under light anesthesia (similar procedure to pump implantation) and the data were collected for another period after cessation of nicotine or saline administration (Day 9 to Day 14).

Experimental protocol has been approved by local Ethical Committee.

\section{Statistical Analysis}

Because infusions in females were all started on a particular day of their 5-days estrous cycle (metestrous - see above), the data are expressed as related to cycle-synchronized days.

To describe the data from the period of nicotine infusion (Day 1 to Day 7), means \pm SE were calculated for body weight, food intake, meal number and meal size. Furthermore, the means were expressed as the percentage of control data (Table 1).

The data in female rats are presented per complete four estrous cycles (Day -6 to Day 14), to demonstrate their particular cyclical feeding pattern, while the data in naturally non-cycling males are shown from Day -1 to Day 11.

All data are expressed as mean \pm SE. The two-tailed Student's t-test was used to compare control vs. nicotine rats. 
Table 1: Body weight, food intake, meal number and meal size during nicotine administration. Data are presented as average \pm SE for the total of $7 \mathrm{~d}$ period of nicotine infusion (Day 1 to Day 7). The percentage change in nicotine treated animals, assuming the values in control rats being $100 \%$, is also indicated.

Daily mean $( \pm$ SE) of body weight, food intake, meal number and meal size during nicotine or saline infusion (Day 1 - Day 7)

\begin{tabular}{|c|l|c|c|c|c|}
\hline \multicolumn{2}{|c|}{} & $\begin{array}{c}\text { Body } \\
\text { weight } \\
(\mathrm{g})\end{array}$ & $\begin{array}{c}\text { Food } \\
\text { intake } \\
(\mathrm{g})\end{array}$ & $\begin{array}{c}\text { Meal } \\
\text { number }\end{array}$ & $\begin{array}{c}\text { Meal } \\
\text { size } \\
(\mathrm{g})\end{array}$ \\
\hline \multirow{4}{*}{ Male } & Nicotine & $274 \pm 7$ & $14.0 \pm 0.7$ & $14.0 \pm 1.3$ & $1.04 \pm 0.10$ \\
\cline { 2 - 7 } & Control & $286 \pm 4$ & $15.9 \pm 0.8$ & $13.5 \pm 1.3$ & $1.23 \pm 0.16$ \\
\cline { 2 - 7 } & $\begin{array}{l}\text { Nicotine as ratio } \\
\text { of } 100 \% \text { Control }\end{array}$ & $96 \%$ & $88 \%$ & $104 \%$ & $85 \%$ \\
\hline \multirow{4}{*}{ Female } & Nicotine & $174 \pm 2$ & $9.2 \pm 0.5$ & $19.3 \pm 2.1$ & $0.52 \pm 0.05$ \\
\cline { 2 - 7 } & Control & $180 \pm 2$ & $10.6 \pm 0.4$ & $17.4 \pm 2.1$ & $0.65 \pm 0.08$ \\
\cline { 2 - 7 } & $\begin{array}{l}\text { Nicotine as ratio } \\
\text { of } 100 \% \text { Control }\end{array}$ & $97 \%$ & $87 \%$ & $110 \%$ & $80 \%$ \\
\hline
\end{tabular}

\section{Results}

\section{Body weight}

The body weights in male $(284 \pm 3 \mathrm{~g}$ in control vs. 283 $\pm 8 \mathrm{~g}$ in nicotine group) and female ( $177 \pm 2 \mathrm{~g}$ in control vs. $178 \pm 2 \mathrm{~g}$ in nicotine group) did not differ significantly before nicotine administration on Day 0. During the period of nicotine administration there was an inverse relationship between nicotine administration and body weight. Both sexes gained significantly less body weight compared to the controls. The daily average weight gain was $97 \%$ of control values in female and $96 \%$ in male nicotine-treated rats (Table 1). After cessation of nicotine administration, all rats increased the body weight gain. In spite of this, the body weight in nicotine-administered vs. control rats was still significantly lower on Day 11 (male rats: $297 \pm 4 \mathrm{~g}$ in control vs. $279 \pm 7 \mathrm{~g}$ in nicotine group, $\mathrm{p}<0.05$; female rats: $183 \pm 2 \mathrm{~g}$ in control vs. $177 \pm 2 \mathrm{~g}$ in nicotine group, $\mathrm{p}<0.05)$.

\section{Food Intake}

The average daily food intake during nicotine administration was $88 \%$ of the control values in male and $87 \%$ in female rats (Table 1). As shown in Figure 1, daily food intake in the female rats fluctuated. Before nicotine administration, peak food intake was reached during the metestrous and diestrous phases, while a nadir occured during late proestrous and estrous phases. Anesthesia and surgery on Day 0 decreased the food intake in both sexes. The female rats did not lose their cyclical pattern during the period of nicotine infusion from Day 0 - Day 8 . The food-depressing effect of nicotine was significant on Days 1, 2, 3, 4, 6 and 8 in females and/or by Days 1 and 4 in males vs. controls.
The food intake in the male and female rats returned to normal by Day 9 .

Fig. 1: Daily means \pm SE of food intake in male (top) and female (bottom) rats before (Day -6 to Day -1), during (Day 1 to Day 7) and after cessation of nicotine administration (Day 9 to Day 14). The mini-osmotic pumps for nicotine delivery were surgically inserted on Day 0 and removed on Day 8. Statistical significance of the difference at $p<0.05 \mathrm{ni}-$ cotine vs. control is indicated by asterisks above relevant data points. The period of nicotine administration is indicated by shadow bars. The numbers on $\mathrm{X}$ axis indicate the days from mini-osmotic pumps insertion, and are used both for male and female. The letters on $\mathrm{X}$ axis indicate the phase of the female estrous cycle: M, metestrous; D, diestrous; $\mathrm{P}$, early or late proestrous; E, estrous.

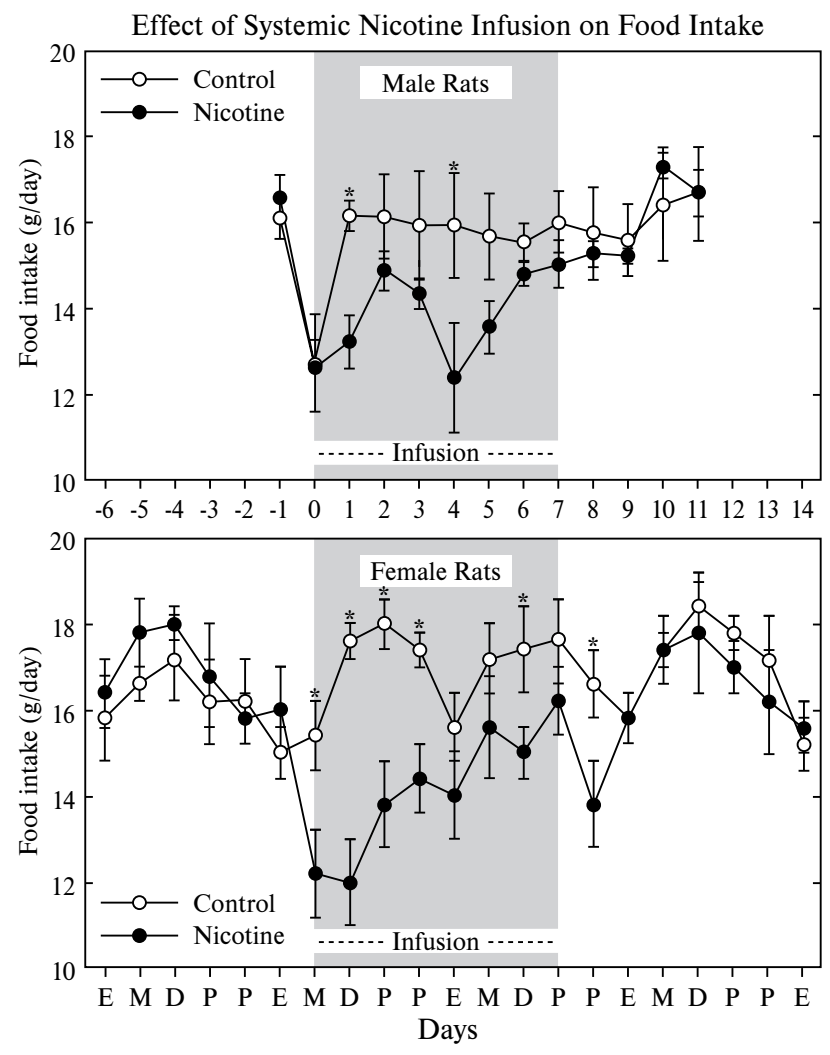

\section{Meal Number}

In spite of the decreased food intake during nicotine administration, the meal number did not change significantly in either male and female rats, as compared vs. controls (Figure 2). The average meal number during nicotine administration was $104 \%$ of the control values in male and $110 \%$ in female rats (Table 1). In females, daily meal number fluctuated. Before nicotine administration, peak meal number was reached during the late proestrous phase, and this cyclical pattern was not changed during nicotine administration. 
Fig. 2: Daily means $\pm \mathrm{SE}$ of meal number in male (top) and female (bottom) rats before (Day -6 to Day -1 ), during (Day 1 to Day 7) and after cessation of nicotine administration (Day 9 to Day 14). The mini-osmotic pumps for nicotine delivery were surgically inserted on Day 0 and removed on Day 8. There was no statistical significance of the differences between means. The period of nicotine administration is indicated by shadow bars. The numbers on $\mathrm{X}$ axis indicate the days from mini-osmotic pumps insertion, and are used both for male and female. The letters on $\mathrm{X}$ axis indicate the phase of the female estrous cycle: $\mathrm{M}$, metestrous; D, diestrous; P, early or late proestrous; E, estrous.
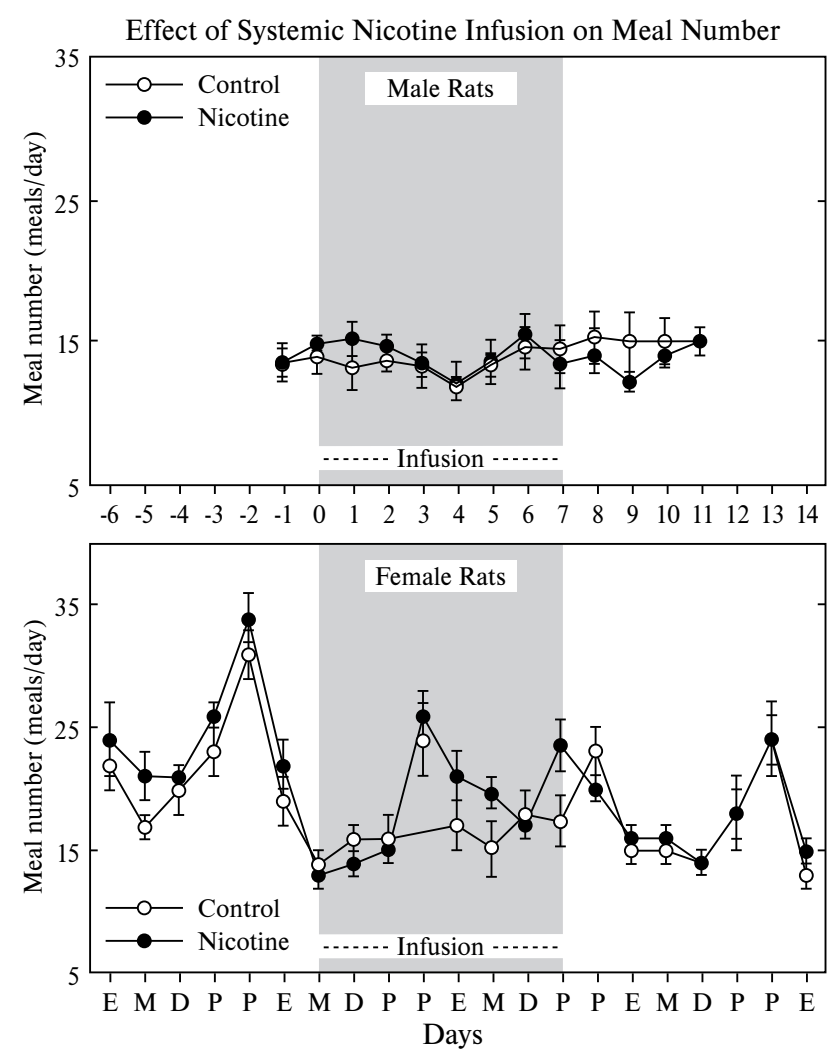

Meal Size

The food-depressing effect of nicotine in both sexes was due to the significantly decreased meal size (Figure 3 ) on Days 1, 3, 4, 5 and 7 in females vs. controls and/or on Days 1 and 4 in males vs. controls. After cessation of nicotine administration, the meal size became normal. The average meal size during nicotine administration was $85 \%$ of the control values in male and $80 \%$ in female rats (Table 1 ). In females, daily meal size fluctuated. Before nicotine administration, a nadir was reached during the late proestrous phase, and this cyclical pattern was not changed during nicotine administration.
Fig. 3: Daily means \pm SE of meal size in male (top) and female (bottom) rats before (Day -6 to Day -1), during (Day 1 to Day 7) and after cessation of nicotine administration (Day 9 to Day 14). The mini-osmotic pumps for nicotine delivery were surgically inserted on Day 0 and removed on Day 8. Statistical significance of the difference at $p<0.05$ nicotine vs. control is indicated by asterisks above relevant data points. The period of nicotine administration is indicated by shadow bars. The numbers on $\mathrm{X}$ axis indicate the days from mini-osmotic pumps insertion, and are used both for male and female. The letters on $\mathrm{X}$ axis indicate the phase of the female estrous cycle: $\mathrm{M}$, metestrous; $\mathrm{D}$, diestrous; $\mathrm{P}$, early or late proestrous; E, estrous.

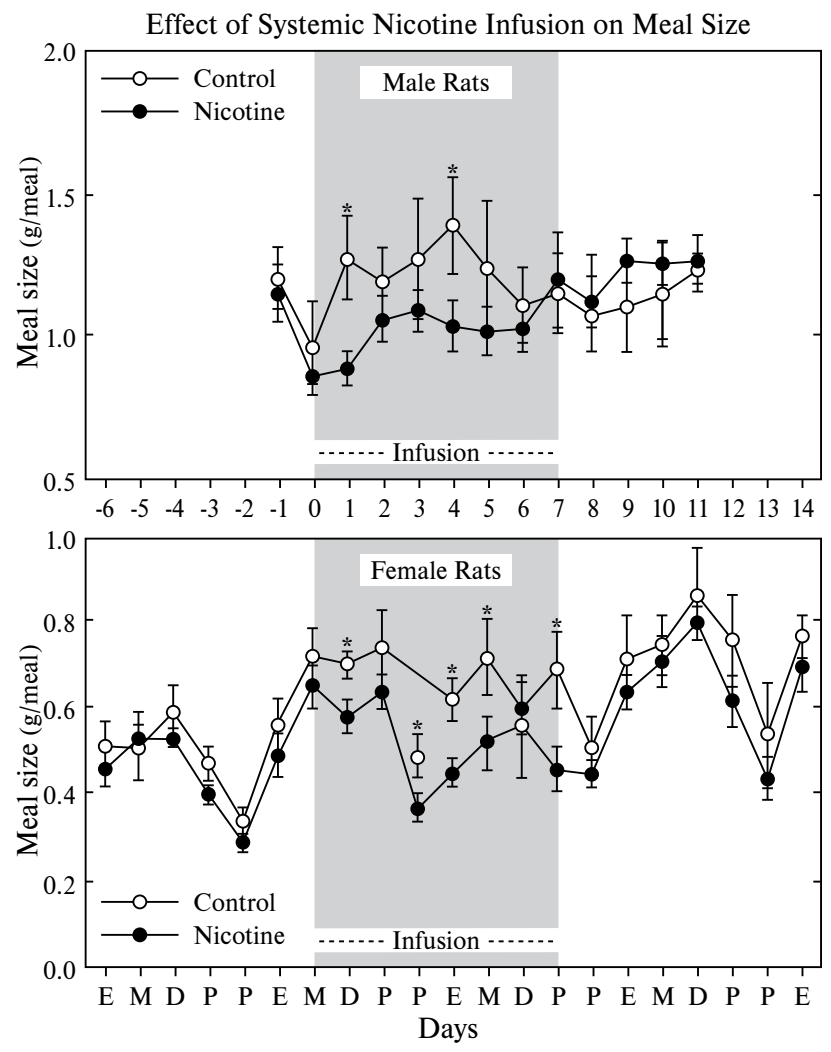

\section{Discussion}

In the present study, mini-osmotic pumps and automated rat eatometer were used to evaluate the feeding pattern of male and female Fischer 344 rats during seven days of systemic nicotine infusion. The main findings are: 1) systemic nicotine infusion decreased food intake in both sexes; 2) the decreased food intake was due to significantly reduced meal sizes while meal numbers were not altered significantly both in males and females; 3 ) the cyclical pattern among vaginal smears, food intake, meal number and meal size of female rats was not affected by nicotine administration. 
The findings of this study indicate that nicotine administration decreases food intake via a selective suppression of meal size, and thus satiation. It has been suggested that satiation of feeding is the principal mechanism of food regulation and is primarily responsible for the adjustment of food intake to the extent of a nutritional deficit (6). However, our results did not address the mechanisms that may underlie the influence of nicotine on meal size. We propose both a peripheral and a central interaction: The first possibility is that nicotine affects the brain areas regulating meal size. Thus, nicotine and its agonists, through an interaction at nicotine receptors in brain, facilitate the release of many neurotransmitters, including acetylcholine, norepinephrine, dopamine and serotonin $(27,29,36,42)$. Among the neurotransmitters, dopamine release in lateral hypothalamic area (LHA) was significantly increased by eating (40), and the degree of increase correlated with meal size (22). LHA-dopamine is a potent eating-inhibitory neurotransmitter (15), and consistent evidence indicates that LHA-dopamine controls meal size via the modulation of gastric motility (26).

The second possibility is that systemic nicotine increases the brain serotonin release $(27,36)$. Serotonin is a well established eating-inhibitory neurotransmitter in medial hypothalamus (15). In vivo microdialysis studies report that setting up satiation during the meal is mediated by sharp serotonin release in this hypothalamic area (24), thus probably regulating meal size.

The third aspect of the central interaction of systemic nicotine and meal size regulation comprises the influence of nicotine upon locomotor activities connected with feeding. High doses of nicotine reduce spontaneous locomotor activity (11), and decrease food intake, the time spent investigating the food, and time rearing and grooming, but increase the time spent resting (16). Moreover, systemic nicotine influences other centrally regulated mechanisms, which might decrease food intake via reduced meal size, by decreasing the water ingestion $(16,34)$, by acting as a substitute for oral behaviors (12), by altering taste perception (6) or by increasing the metabolic rate (33).

Finally, nicotine influences peripheral bioavailability of nutrients. Such interaction could decrease meal size by promoting early satiation. Thus gastrointestinal secretion and motility has been reported to be delayed in individuals who smoke (30). Since the gastric emptying rate, as reflected by the number of pellets expelled per time, was reduced in rats given nicotine (25), this might affect nutrient absorption and decrease food intake via reduced meal size. How nicotine enhances satiation via a suppression of meal size may include its effect on fat stores (37), or by a significant decrease in circulating insulin levels and increase in catecholamines and glucose (10). The resulting hyperglycemia and/or higher rate of fat catabolism could be associated with early satiation, and thereby with decrease of individual meal size.

Feeding in female rats is primarily influenced by sex-linked hormones (32), reflecting their cyclical pattern
$(5,14,38)$. Nicotine induced changes in feeding were suggested to be gender-related $(8,9)$, and interaction of nicotine with sex steroids was proposed (18). Evidence from the present study does not support the hypothesis that the feeding suppressive effect of nicotine in the rat is mediated via female sex-linked hormones. The average decrease in daily food intake was similar in both sexes, as shown in Figures 1-3 and Table 1 . The feeding suppressive effect of nicotine was due to the reduced meal size both in male and female rats. The daily vaginal smears in the females showed regular 5 days cycling, as did the cyclical feeding pattern. Thus, nicotine administration did not alter the female estrous cycle, which is regulated via female sex hormones.

The effect of nicotine on regulation of feeding behavior is a complex process that includes both central and peripheral mechanismus, althought our study was not designed to elucidate the particular mechanismus. A selective effect of nicotine on satiation via decrease in meal size accounted for the depressed food intake in our study. Therefore, we hypothesize, that the central feeding suppressive effect of nicotine might be mediated via 1) increased hypothalamic dopaminergic and/or serotonergic activity, 2) decrease in locomotor activity, 3) by acting as a substitute for oral behaviors or by altering taste perception, or 4) by increasing the metabolic rate (33). In the periphery, the delayed gastrointestinal transit time or the hormonal changes of decreased insulinemia and resulting hyperglycemia or increased fat catabolism, might account for the reduced meal size during nicotine administration. The particular role of hypothalamic feeding-related centers and their neurotransmitters in mediating the central feeding suppressive effect of nicotine is currently under investigation. Recognition of this suggests to promise of approaching appetite control by drugs. Instead of searching for compounds that inhibit food intake, an alternative strategy would be to consider compounds that intensify the satiating power of food. In other words, drugs would not work to directly block intake but would work synergistically or additively with food itself to create an enhanced satiating efficiency.

\section{Acknowledgment}

We thank Darlene Thompson and Willam G. Hammond for their editorial assistance.

This work was supported in part by grant IGA MH CR 4548-3.

\section{References}

1. Audrain JE, Klesges RC, Klesges LM. Relationship between obesity and the metabolic effects of smoking in women. Health Psychol 1995;14:116-23.

2. Beckett AH, Gorrod JW, Jenner P. The effect of smoking on nicotine metabolism in vivo in man. J Pharm Pharmacol 1971;23:62S-67S. 
3. Benowitz NL, Jacob P. Daily intake of nicotine during cigarette smoking. Clin Pharmacol Ther 1984;35:499-504.

4. Bláha V, Meguid MM, Yang Z-J et al. Correlation of meal size and number to plasma concentration of sex-linked hormones during a 4-day rat estrous cycle. Physiol Behav submitted.

5. Butcher RL, Collins WE, Fugo NW. Plasma concentration of $\mathrm{LH}, \mathrm{bFSH}$, prolactin, progesterone and estradiol-17 throughout the 4-day estrous cycle of the rat. Endocrinology 1974;94:1704-8.

6. Collier G. The economics of hunger, thirst, satiety, and regulation. Ann N Y Acad Sci 1989;575:136-54.

7. Grunberg N. The effects of nicotine and cigarette smoking on food comsumption and taste preferences. Addict Behav 1982;7:317-31.

8.Grunberg NE, Bowen DJ, Morse DE. Effects of nicotine on body weight and food consumption in rats. Psychopharmacology 1984;83:93-8.

9.Grunberg NE, Bowen DJ, Winders SE. Effects of nicotine on body weight and food consumption in female rats. Psychopharmacology 1986;90:101-5.

10.Grungerg NE, Popp KA, Bowen DJ, Nespor SM, Winders SE, Eury SE. Effects of chronic nicotine administration on insulin, glucose, epinephrine, and norepinephrine. Life Sci 1988;42:161-70.

11.Grunwald F, Schrock H, Theilen H, Biber A, Kuschinsky W. Local cerebral glucose utilization of the awake rat during chronic administration of nicotine. Brain Res 1988;456:350-6.

12.Jacobs MA, Knapp PH, Anderson LS, Karnsh N, Meissner R, Richman SJ. Relationship of oral frustration factors with heavy cigarette smoking in male college students. J Nerv Ment Dis 1965;141:161-71.

13.Kozlowski LT, Director J, Harford MA. Tobacco dependence; restraint and time to the first cigarette of the day. Addict Behav 1981;6:307-12.

14.Laviano A, Meguid MM, Gleason JR, Yang Z-J, Renvyle T. Comparison of long-term feeding pattern between male and female Fischer 344 rats: influence of estrous cycle. Am J Physiol 1996;270:R413-R419.

15.Leibowitz SF. Brain monoamines and peptides: role in the control of eating behavior. Feder Proc 1986;45:1396-1403.

16.Levin ED, Ellison GD, Salem C, Jarvik M, Gritz E. Behavioral effects of acute hexamethonium in rats chronically intoxicated with nicotine. Physiol Behav 1988;44:355-9. 17.Levin ED, Briggs SJ, Christopher NC, Rose JE. Sertraline attenuates hyperphagia in rats following nicotine withdrawal. Pharmacol Biochem Behav 1993;44:51-61.

18.McNair E, Brysson R. Effects of nicotine on weight change and food consumption in rats. Pharmacol Biochem Behav 1983;18:341-4.

19.Meguid MM, Kawashima Y, Campos ACL ett al. Automated computerized rat eater meter: description and application. Physiol Behav 1990;48:759-63.

20.Meguid MM, Chen T-Y, Yang Z-J, Campos ACL, Hitch DC, Gleason JR. Effects of continuous graded total paren- teral nutrition on feeding indexes and metabolic concomitants in rats. Am J Physiol 1991;260:E126-E140.

21.Meguid MM, Gleason JR, Yang Z-J. Olfactory bulbectomy in rats modulates feeding pattern but not total food intake. Physiol Behav 1993;54:471-5.

22.Meguid MM, Yang Z-J, Koseki M. Eating induced rise in LHA-dopamine correlates with meal size in normal and bulbectomized rats. Brain Res Bull 1995;36:487-90.

23.Murrin LCH, Ferrer JT, Wanyun Z, Haley NJ. Nicotine administration to rats: methodological considerations. Life Sci 1987; 17:1699-1708.

24.Orosco M, Nicolaidis S. Spontaneous feeding-related monoaminergic changes in the rostromedial hypothalamus revealed by microdialysis. Physiol Behav 1992;52:1015-9.

25.Qiu BS, Cho CH, Ogle CW. The influence of chronic nicotine on stress-induced gastric ulceration and emptying rate in rats. Experientia 1992;48:389-91.

26.Ralph TL, Sawchenko PE. Differential effects of lateral and ventromedial hypothalamic lesions on gastrointestinal transit in the rat. Physiol Behav 1978;3:11-4.

27.Ribeiro EB, Bettiker RL, Bogdanov M, Wurtman RJ. Effect of systemic nicotine on serotonin release in rat brain. Brain Res 1993;621:311-8.

28. Rosecrans J. A. Brain area nicotine levels in male and female rats with different levels of spontaneous activity. Neuropharmacology 1972;11:863-70.

29.Rowell PP, Winkler DL. Nicotinic stimulation of $\left[{ }^{3} \mathrm{H}\right]$ acetylcholine release from mouse cerebral cortical synaptosomes. J Neurochem 1984;43:1593-8.

30.Scott AM, Fracp JEK, Fracp GME, Nolan JM, Jones MP. Cigarette smoking and nicotine delay postprandial mouth-cecum transit time. Digest Dis Sci 1992;37:15447.

31.Stolerman IP, Mirza NR, Shoaib M. Nicotine psychopharmacology: addiction, cognition and neuroadaptation. Med Res Rev 1995;1:47-72.

32. Wade GN, Schneider JI. Metabolic fuels and reproduction in female mammals. Neurosci Biobehav Rev 1992; 16:235-72.

33. Wack JT, Rodin JR. Smoking and its effects on body weight and the systems of caloric regulation. Am J Clin Nutr 1982;35:366-80.

34.Wager-Srdar SA, Levine AS, Morley JE, Hoidal JR, Niewoehner DE. Effects of cigarette smoke and nicotine on feeding and energy. Physiol Behav 1984;32:389-95.

35. Waynforth HG, Flecknell PA. Reproductive parameters. In: Harcout; Brace; Jovanovich, eds. Experimental and Surgical Technique in the Rat. New York: Academic Press; 1992.

36. Westfall PJ, Grant H, Perry H. Release of dopamine and 5-hydroxytryptamine from rat striatal slices following activation of nicotinic cholinergic receptors. Gen Pharmacol 1983; 14:321-5.

37.Winders SE, Grunberg NE. Effects of nicotine on body weight, food consumption and body composition in male rats. Life Sci 1990;46:1523-30. 
38.Wingkar KC. Alterations in feeding and sexual behavior during reproductive cycle in female rats. Indian $\mathrm{J}$ Physiol Pharmacol 1992;36:174-6.

39. Yang Z-J, Ratto C, Gleason JR, Bellantone R, Crucitti F, Meguid MM. Influence of anterior subdiaphragmatic vagotomy and TPN on rat feeding behavior. Physiol Behav 1992;51:919-26.

40.Yang Z-J, Meguid MM. LHA dopaminergic activity in obese and lean Zucker rats. NeuroReport 1995;6:1191-4.

41.Yang Z-J, Meguid MM, Chai J-K, Chen Ch, Oler A. Bilateral hypothalamic dopamine infusion in Zucker rats supresses feeding due to reduced meal size. Pharmacol Biochem Behav 1996, submitted.

42.Yoshida K, Kato Y, Imura H. Nicotine-induced release of noradrenaline from hypothalamic synaptosomes. Brain Res 1980;182:361-8.

Submitted July 1998.

Accepted October 1998.

MUDr. Vladimír Bláha, CSc., Dept. of Metabolic Care and Gerontology, Charles University, Faculty of Medicine and Teaching Hospital, 50005 Hradec Králové, Czech Republic. 